BIOKEMISTRI 17(2):107-114 (Dec 2005)

Available online at http://www.bioline.org.br/bk.

Abstracted online at www.ajol.info/journals/biokem

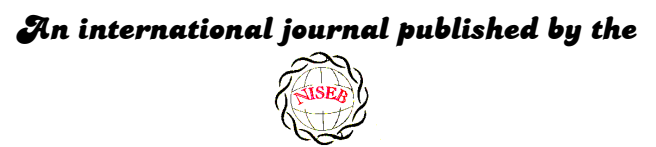

OVigerian Society for E̊xperimental \&iology

Printed in Nigeria

\title{
Serum antioxidant vitamins levels in non- insulin- dependent diabetes mellitus subjects in Sokoto, Nigeria
}

\author{
Muhammad ALIYU ${ }^{1}$, Mansur LAWAL ${ }^{1}$, Frank MOJIMINIYI ${ }^{2}$, Yusuf SAIDU ${ }^{1,}$ and \\ Lawal S. BILBIS ${ }^{1}$ *
${ }^{1}$ Department of Biochemistry, ${ }^{2}$ Deparment of Human Physiology, Usmanu Danfodiyo University, Sokoto, Nigeria

Received 7 May 2005

MS/No BKM/2005/023, @ 2005 Nigerian Society for Experimental Biology. All rights reserved.

\begin{abstract}
Evidence is accumulating that most of the degenerative diseases including diabetes mellitus have their origin in deleterious free radical reactions. Humans are well endowed with antioxidant defences primarily by free radical scavengers, such as ascorbic acid, alpha-tocopherol, beta-carotene, and trace elements. Deficiencies of these micronutrients may increase susceptibility to these diseases and the associated complications. Antioxidant vitamins (vitamins A, E and C) were estimated in one hundred and fifty (150) non insulin dependent diabetes mellitus (NIDDM) patients attending the outpatient clinic of the Usmanu Danfodiyo University Teaching Hospital, Sokoto, Nigeria. The results obtained were compared to those of One hundred and fifty (150) apparently healthy non-diabetic subjects. Serum glucose of the diabetic patients $(13.59 \pm 4.85 \mathrm{mM})$ was significantly higher $(\mathrm{P}<0.05)$ than the control value $(5.19 \pm 1.15 \mathrm{mM})$. Vitamins $\mathrm{A}, \mathrm{E}$ and $\mathrm{C}$ concentrations were significantly lower $(\mathrm{P}<0.05)$ in diabetic patients. Twenty Nine percent of the male and female diabetic patients had severe vitamin A deficiency (VAD) while $23 \%$ and $16 \%$ of them respectively had moderate $\mathrm{VAD}$. The prevalence of vitamins $\mathrm{C}$ and $\mathrm{E}$ deficiencies among NIDDM subjects was also high. The results indicated significant $(\mathrm{P}<0.05)$ negative correlation between serum glucose and each of the antioxidant vitamin levels $(r=-0.41,-0.5$ and $\quad-0.05$ for vitamins $A, E$ and $\mathrm{C}$ respectively). These results suggest that NIDDM subjects of the study area have low serum levels of antioxidant vitamins and the concentration of these vitamins correlated negatively with blood glucose level.
\end{abstract}

Key words: Antioxidant vitamins, non-insulin dependent diabetes mellitus, Sokoto

*Author to whom all correspondence should be addressed.

E-mail: 1sbilbis@udusok.edu.ng; Tel: 08034227001 


\section{INTRODUCTION}

Diabetes Mellitus, a chronic disease characterized by high levels of blood glucose resulting from defects in insulin secretion, insulin action, or both. It is a multi system disease that is widespread throughout the world, affecting carbohydrate, protein and lipid metabolisms. The prevalence varies greatly between communities. In Britain, it constitutes about $3 \%$ of the total population ${ }^{1}$. In U.S.A 15.7 million people, nearly $6 \%$ of the population has the disease ${ }^{2}$. The global estimate of people living with diabetes mellitus as at 2000 is $2.8 \%$; this is expected to reach $4.4 \%$ by $2030^{3}$.

In African communities, the prevalence is increasing with ageing of the population and life style changes associated with urbanisation ${ }^{4}$. It is known to affect 3\%, on the average, of adult Nigerians ${ }^{5}$. The prevalence of diabetes in suburban population of Northern Nigeria is $1.6 \%{ }^{6}$. There are 2 major types of clinical diabetes mellitus: type 1, also known as insulin dependent diabetes mellitus (IDDM) and type 2 otherwise called non-insulin dependent diabetes mellitus (NIDDM). Type 2 diabetes is the most common form, accounting for about $90 \%$ of all cases $^{4}$. It is a metabolic disorder, resulting from the body's insensitivity to insulin. It occurs more frequently in people who are overweight, inactive and usually older than 40 years of age ${ }^{7}$. Most people with type 2 diabetes do not need insulin to prevent death as a result of ketoacidosis ${ }^{7}$.

Diabetes is a free radical associated disease. Investigations carried out in diabetic patients revealed oxidative stress $\operatorname{load}^{8}$. Oxidative destruction of subcellular membrane lipids has been implicated along with other types of intracellular oxidative damage in the normal aging process and in pathophysiology of a number of chronic illnesses. Complex antioxidant mechanism, including antioxidant vitamins, exists to limit the effects of these reactions ${ }^{9}$.

The developments of diabetic late complications (cataract, retinopathy, nephropathy and neuropathy) are associated with an increased presence of free radicals, and, therefore elevated oxidative stress of the human body ${ }^{8}$. Thus diabetics elicit a higher rate of blindness, kidney disease, gangrene and coronary heart disease several times more than non-diabetics. Quite a number of antioxidants participate in the protection of human body against free radical pathology and its consequences. They include vitamins $\mathrm{E}, \mathrm{A}$ and $\mathrm{C}$ and other micronutrients such as zinc, chromium, selenium and vanadium $^{10}$.

Since it appears that there is dearth of reports on antioxidant status of diabetic patients in this part of the world, this study is an attempt to estimate the serum concentrations of some antioxidant vitamins: Vitamins $\mathrm{A}, \mathrm{C}$ and $\mathrm{E}$ in non-insulindependent diabetes mellitus patients in SokotoNigeria.

\section{MATERIALS AND METHODS}

\section{Subjects}

The subjects employed for this study were 150 diabetic patients (NIDDM) of both sexes who were attending the medical Outpatient clinic of Usmanu Danfodiyo University Teaching Hospital (UDUTH), Sokoto, Nigeria. One hundred and fifty apparently healthy volunteers who were Youth Corps Members, Nurses and Student Nurses of UDUTH, Sokoto were also recruited to serve as control. The consent of both diabetics and control subjects were however sought and obtained. Only those subjects who consented were included in the current study. Thirty seven percent of the diabetics and $33 \%$ of the control subjects were females. Information on the age, weight, height and nature of occupation of the subjects was obtained.

\section{Blood samples}

Fasting blood samples were obtained after an 812 hour overnight fast, from the subjects by veno-puncture. The blood samples were centrifuged at $1000 \mathrm{rpm}$ for 20 minutes using a desktop centrifuge. Serum glucose was estimated by glucose oxidase method within few hours of sample collection. The remaining 
portion of serum samples was stored at $-20^{\circ} \mathrm{C}$, until required for the estimation of antioxidant vitamins.

\section{Reagents}

Glucose oxidase assay kits were obtained from Randox Laboratories Switzerland. All other chemicals and reagents were of analytical grade and purchased from Sigma Chemical Company USA. USP reference vitamins A and E capsules were used. Vitamin C standard was obtained from Fischer Scientific Co. UK.

\section{Analytical methods}

Serum glucose was estimated using the glucose oxidase method of Trinder ${ }^{11}$. Vitamin A was estimated by a modification of the spectrophotometric method described by Neild and Pearson ${ }^{12}$. In this method, the conjugated double bonds of vitamin $\mathrm{A}$ are reacted with trifluoroacetic acid (TFA) forming a faint, short lived, blue compound that can be read spectrophotometrically. A correction factor to account for carotenes reaction with TFA was worked out ${ }^{12}$. Vitamin $\mathrm{E}$ was determined by a modification of the micro method described by Quaife and co-workers ${ }^{13}$; in which tocopherols reduce ferric to ferrous ions. Carotenoids interfere with the assay and thus absorbance due to carotenes is subtracted. Serum ascorbic acid was determined by the method of Lowry et $a l^{14}$.

\section{RESULTS}

Table 1 shows the general characteristics of the subjects. The diabetic patients were generally heavier than the control subjects were. The result of the body mass index (BMI) indicated that the diabetic subjects were over weight.

Mean serum values of fasting blood sugar (FBS) and antioxidant vitamins of NIDDM and apparently healthy non-diabetic control subjects are presented in table 2 . There was a significant difference $(p<0.05)$ between serum glucose level of the diabetics and non-diabetics. When separated on the basis of gender, the results showed no significant difference $(\mathrm{P}<0.05)$. Serum antioxidant vitamins were higher $(\mathrm{P}<0.05)$ in normal subjects. Prevalence of hypovitaminosis among diabetics is wide spread in the study area. As indicated in tables 3, thirty two percent, $13 \%$ and $37 \%$ of the subjects had severe vitamins $\mathrm{A}, \mathrm{E}$ and $\mathrm{C}$ deficiencies respectively. Correlation between serum glucose and antioxidant vitamins (Table 4) indicated significant $(\mathrm{P}<0.05)$ negative correlation in the diabetic subjects.

Table 1: General Characteristics of NIDDM and Normal subjects

\begin{tabular}{cccccc}
\hline Subjects & $\mathrm{n}^{*}$ & Weight $(\mathrm{Kg})$ & Height $(\mathrm{m})$ & BMI** $\left.^{*} \mathrm{Kg} / \mathrm{m}^{2}\right)$ & Age (years) \\
\hline Normal & & & & & \\
Male & 104 & $59.7 \pm 7.2$ & $1.65 \pm 0.15$ & $21.93 \pm 1.2$ & $30.3 \pm 7.2$ \\
Female & 61 & $57.2 \pm 6.9$ & $1.54 \pm 0.08$ & $24.12 \pm 0.9$ & $29.3 \pm 5.4$ \\
Total & 165 & $58.4 \pm 7.3$ & $1.59 \pm 0.11$ & $23.11 \pm 1.3$ & $30.0 \pm 6.9$ \\
NIDDM & & & & & \\
Male & 100 & $67.3 \pm 10.4$ & $1.63 \pm 0.14$ & $25.33 \pm 2.1$ & $40.3 \pm 7.3$ \\
Female & 50 & $68.1 \pm 6.5$ & $1.58 \pm 0.07$ & $27.28 \pm 2.4$ & $38.1 \pm 6.5$ \\
Total & 150 & $67.7 \pm 8.7$ & $1.60 \pm 0.10$ & $26.45 \pm 2.3$ & $39.2 \pm 7.3$ \\
\hline \multicolumn{5}{c}{$* n=$ number of subjects } & $* *$ BMI $=$ Body mass index $=$ weight/height
\end{tabular}


Table 2: Serum Glucose and Antioxidant Vitamin Levels of NIDDM and Normal Subjects*

\begin{tabular}{lccccc}
\hline Subjects & $\mathrm{n}$ & \multicolumn{4}{c}{ Parameters** } \\
\cline { 3 - 6 } & & FBS(mmol/L) & $\begin{array}{c}\text { Serum Vitamin } \\
\text { A }(\mu \mathrm{g} / \mathrm{dl})\end{array}$ & $\begin{array}{c}\text { Serum Vitamin E } \\
(\mathrm{mg} / \mathrm{dl})\end{array}$ & $\begin{array}{c}\text { Serum Vitamin } \\
\mathrm{C}(\mathrm{mg} / \mathrm{dl})\end{array}$ \\
\hline Normal & & & & & \\
$\quad$ Male & 95 & $4.31 \pm 0.53$ & $44.06 \pm 14.38$ & $0.87 \pm 0.15$ & $0.95 \pm 0.15$ \\
Female & 55 & $4.17 \pm 0.44$ & $46.97 \pm 14.03$ & $0.88 \pm 0.16$ & $0.99 \pm 0.21$ \\
Total & 150 & $4.24 \pm 0.51$ & $45.12 \pm 13.88$ & $0.88 \pm 0.15$ & $0.97 \pm 0.18$ \\
NIDDM & & & & & \\
Male & 100 & $13.30 \pm 1.11$ & $14.47 \pm 7.91$ & $0.64 \pm 0.22$ & $0.56 \pm 0.19$ \\
Female & 50 & $14.06 \pm 2.28$ & $14.34 \pm 8.32$ & $0.57 \pm 0.18$ & $0.56 \pm 0.17$ \\
Total & 150 & $13.59 \pm 2.85$ & $14.42 \pm 8.02$ & $0.62 \pm 0.20$ & $0.56 \pm 0.18$ \\
\hline
\end{tabular}

*Values are expressed as mean \pm Standard Deviation, $n=$ number of subjects, **values differ significantly $(P<0.05)$ between the control and diabetes, FBS $=$ Fasting Blood sugar

Table 3: Percentage of Subjects With Hypovitaminosis*

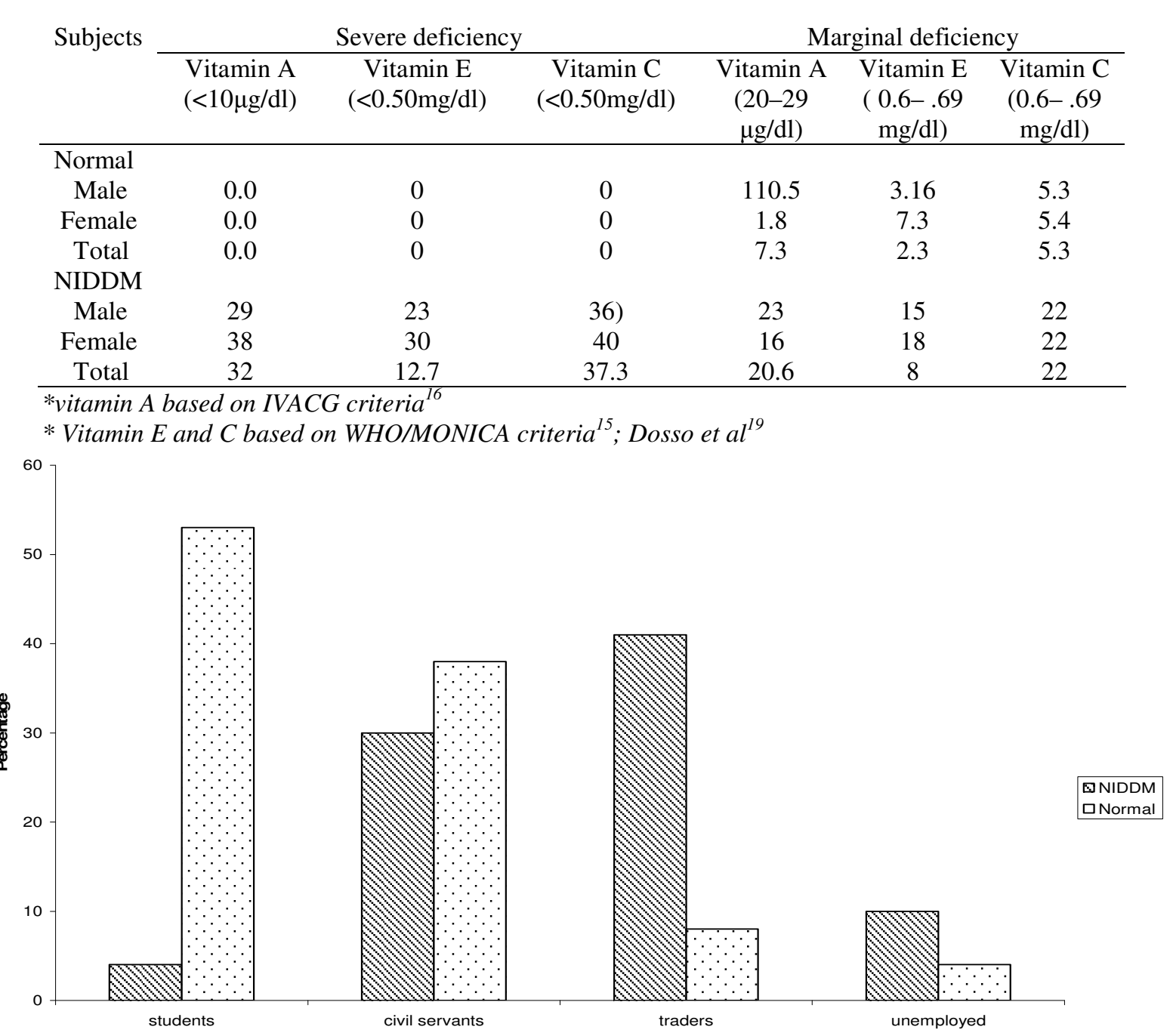

Fig 1: Employment Status of NIDDM and Normal Subjects in Sokoto Nigeria 
Table 4: Correlation Coefficient (r) of Fasting Blood Sugar and Antioxidant Vitamins of Diabetic and Normal Subjects

\begin{tabular}{cccc}
\hline Subjects & \multicolumn{3}{c}{ Correlation Coefficient (r) } \\
\hline & $\begin{array}{c}\text { Vitamin } \\
\text { A }\end{array}$ & $\begin{array}{c}\text { Vitamin } \\
\text { E }\end{array}$ & $\begin{array}{c}\text { Vitamin } \\
\text { C }\end{array}$ \\
\hline Normal & & & \\
Male & -0.17 & 0.016 & 0.09 \\
Female & $-0.29^{*}$ & 0.05 & 0.17 \\
Total & $-0.20^{*}$ & 0.02 & 0.10 \\
NIDDM & & & \\
Male & $-0.42^{*}$ & $-0.6^{*}$ & -0.014 \\
Female & $-0.39^{*}$ & $-0.38^{*}$ & -0.22 \\
Total & $-0.41^{*}$ & $-0.5^{*}$ & -0.05 \\
\hline
\end{tabular}

$* \overline{\text { Values bearing asterisks are significantly correlated }}$ with Fasting blood sugar $(P<0.05)$

\section{DISCUSSION}

The primary need of a diabetic patient is to attain and sustain normoglycemia. His potential problems are largely the complications that could develop as a result of poor management of the disease. Management and treatment of diabetes is difficult due to poor level of education and health care facilities in developing countries. Therefore, reported increase of diabetics in Nigeria has been of great concern $^{5,6}$.

The WHO/MONICA ${ }^{15}$ dual study of antioxidants and that of Cunningham ${ }^{2}$ indicated that normal serum concentration of vitamin A range from 40 to $70 \mu \mathrm{g} / \mathrm{dl}$. Lower acceptable levels are $30 \mu \mathrm{g} / \mathrm{dl}$ for children and $20 \mu \mathrm{g} / \mathrm{dl}$ for adults. Serum concentrations of less than $10 \mu \mathrm{g} / \mathrm{dl}$ are indicative of deficiency and severe depletion of liver stores of vitamin $\mathrm{A}^{16}$. High levels are usually found in toxicity and in individuals receiving diets high in Vitamin $\mathrm{A}^{2}$. Low serum levels of vitamin $\mathrm{A}$ are also found in gastrointestinal, pancreatic and hepatic diseases and in infection, e.g. fever and chronic nephritis ${ }^{17}$. However, women taking steroids or oral contraceptives have been reported to have slightly elevated serum concentrations of Vitamin $\mathrm{A}^{8}$. Vitamin A activity is very important for maintaining health and thus humans and other animals have developed the capacity to store it. Storage lessens the need for regular intake of the vitamin, since it can be mobilized from these stores as retinal bound to retinol binding protein ${ }^{18}$. Liver is the major storage organ for vitamin A, though other tissues such as lungs, eyes, adipose tissue and skin can also store it ${ }^{18}$.

In the current work, mean serum levels of vitamin A recorded for the NIDDM and control subjects were $14.42 \pm 8.02 \mu \mathrm{g} / \mathrm{dl}$ and $45.12 \pm 13.88 \mu \mathrm{g} / \mathrm{dl}$ respectively. Concentration of vitamin A in NIDDM subjects is significantly lower than the values obtained for the control subjects. This is an indication that, NIDDM subjects in the study area are vitamin A deficient. Further analyses of the results revealed that $29 \%$ and $38 \%$ of the male and female diabetic patients respectively have less than $10 \mu \mathrm{g} / \mathrm{dl}$ of vitamin $\mathrm{A}$, a condition considered as severe deficiency state. Additionally, $42 \%$ of male and $38 \%$ of female diabetic patients have moderate vitamin A deficiency $(10-19 \mu \mathrm{g} / \mathrm{dl})$. Furthermore, $23 \%$ of male and $16 \%$ of female diabetic patients had serum vitamin A concentrations within the range of $20-29 \mu \mathrm{g} / \mathrm{dl}$; a marginal deficient state. These are all indicative of deficient states ${ }^{16,19}$. Only about $3.1 \%$ male and $1.8 \%$ of female control subjects, have moderate vitamin A deficiency (10-19 $\mu \mathrm{g} / \mathrm{dl})$. There was no recorded case of severe deficiency (i.e $<10 \underline{\mu g} / \mathrm{dl}$ ) in the control subjects.

Acceptable normal range for Vitamin $\mathrm{E}$ is 0.80 to $1.2 \mathrm{mg} / \mathrm{dl}^{2,15}$. In the current work, reference range obtained for vitamin $\mathrm{E}$ was 0.50 to $1.21 \mathrm{mg} / \mathrm{dl}$. The mean serum vitamin $\mathrm{E}$ obtained for the diabetic patients was significantly lower $(\mathrm{P}<0.05)$ than the values obtained for the control subjects. Further analysis of the results indicated that $72 \%$ and $67 \%$ of female and male diabetic patients respectively were vitamin $\mathrm{E}$ deficient. An individual is considered vitamin $\mathrm{C}$ deficient when his/her serum vitamin $\mathrm{C}$ concentration is less than $0.80 \mathrm{mg} / \mathrm{dl}^{19}$. In the present study, $85 \%$ of male diabetic subjects and $18.5 \%$ of female diabetics had serum vitamin C concentrations below $0.80 \mathrm{mg} / \mathrm{dl}$. 
Many diseases are associated with free radical production. These diseases include among others, diabetes, atherosclerosis and cancer. Consumption of fruits and vegetables is associated with reduced risk of free radical production $^{20}$. The potential protective effects of these foods may be due to their antioxidant vitamin contents. $\beta$-Carotene one of the dietary sources of vitamin $A$, vitamin $C$ and vitamin $E$ are free radical scavengers and have been shown to quench singlet oxygen, superoxide, hydroxy radical and peroxy radicals ${ }^{21}$. The implication of these to the diabetic subjects cannot be overemphasized. In the current work a direct negative correlation between serum antioxidant vitamins $(r=-0.41,-0.5$ and -0.05 for vitamins $\mathrm{A}, \mathrm{E}$ and $\mathrm{C}$ respectively) and fasting blood sugar was observed.

Hyperglycaemia is a recognized pathogenic factor of long-term complications in diabetes mellitus. It does not only generate reactive oxygen species but also attenuates antioxidant mechanism, creating a state of oxidative stress ${ }^{22}$. The beta cells are sensitive to oxidative stress because their intracellular antioxidant defence mechanisms are weak ${ }^{23}$. It is believed that one of the mechanism responsible for secondary complications of diabetes involve nonenzymatic glycosylation of proteins by glucose auto-oxidation $^{24}$. Non enzymatic glycation is a spontaneous chemical reaction between glucose and the amino groups of proteins resulting in the formation of reversible Schiff's bases and Amadori products. These products have been reported to generate free radicals, causing oxidative stress and tissue damage ${ }^{25}$. Antioxidant vitamins such as vitamin $\mathrm{C}$ and $\mathrm{E}$ have been shown to reduce protein glycosylation and act as scavengers of free radicals generated by glycosylated proteins ${ }^{24}$. Cardiovascular complications of diabetes are, in part due to small vessel damage by oxidized low-density lipoprotein (LDL). Vitamin $\mathrm{E}$ was found to lower LDL oxidation, thus lowering the risk of diabetic cardiovascular complications ${ }^{26}$.

It is apparent from the current study that subjects with type 2 diabetes in the study area have low levels of serum antioxidant vitamins. The deficiencies of these vitamins have been implicated in the development of diabetic late complications such as cataract, nephropathy and neuropathy ${ }^{8}$. Some studies suggest that people with diabetes have elevated levels of free radicals and lower level of antioxidants ${ }^{27}$. Some other studies suggested further that vitamin E, Biotin and vitamin B6 supplementation may improve symptoms of diabetes and reduce the risk of associated complications ${ }^{27}$. In a similar study, vitamin E was found to reduce lipid peroxidation stress in type II diabetic subjects with retinopathy ${ }^{28}$. The study further showed that nutrients including vitamin $\mathrm{E}$, vitamin $\mathrm{C}$, magnesium, chromium, lipoic acid and vanadium all have beneficial effects on the symptoms or complications associated with diabetes. Many of these nutrients appear to be closely associated with insulin metabolism and help maintain proper blood glucose levels ${ }^{28}$.

In view of the significantly reduced antioxidants concentrations in NIDDM subjects obtained in this study, and significant negative correlations between serum antioxidant vitamins and fasting blood glucose level of the subjects, it may not be out of place to recommend the inclusion of antioxidant vitamins in therapeutic regimens for the management of NIDDM in particular and diabetes mellitus in general in the study area. This will assist in reducing or delaying the risk of diabetic late complications.

\section{REFERENCES}

1. Diabetes in UK (2004) Diabetes in UK,: A report from Diabetes UK 2004

2. Cunningham, J.J. (1998) Micronutrients as nutriceutical interventions in diabetes mellitus. J. Am. Coll. Nutr. 17:7-10.

3. Sarah, W., Gojka, R., Anders, G., Richard, S. and Hilary, K. (2004) Global prevalence of diabetes. Diabetes Care 27: 1047 - 1053

4. Sobngwi E., Mauvais-Jarvis, F., Vexiau, P., Mbanya, J.C. and Gautier, J.F. (2001) Diabetes in Africans. Diabetes Metab (Paris) 27: $628-634$

5. Akinkugbe, O.O., Yakubu A.M., Johnson T.O., Mabadaje A.F.B., Kaine W.N., 
Ikeme A.C., Akinyanju O.O., Oli J.M., Kuti J.A. and Akintoye C.O. (1992) Noncommunicable diseases in Nigeria. Spectrum Books Limited, Ibadan 1992, 247.

6. Bakari A.G., Onyemekujwe G.C., Sani B.G., Hassan S.S., and Aliyu T.M. (1999) Prevalence of diabetes mellitus in suburban Northern Nigeria: Results of public screening survey. Diabetes Int. 9: 59-60

7. Obrosova I., Cao X., Greene D.A. and Stevens N.J. (1998) Diabetes induced changes in lens antioxidant status, glucose utilization and energy metabolism, effect of alpha lipoic acid. Diabetologia 41: 14421450.

8. Packer L., Peter B., Hans I.T., George I.K. and Philip B. (2000). Antioxidants in diabetes management. Culinary and hospitality publications, 200-248.

9. Packer L.(2002) Alpha Lipoic acid as a biological antioxidants. J. Free Rad. Biol. Med. 20: 1020-1032.

10. Kahler W., Kuklinski B., Rohlmam C. and Plotz C. (1993) Diabetes Mellitus, a free radical associated disease; results of adjuvant antioxidant supplementation. Diabetes 48: 223-232.

11. Trinder P. (1964) Determination of glucose in blood using glucose oxidase with an alternative oxygen acceptor. Annal Clin. Biochem. London. 6: 24-27.

12. Neild C. and Pearson S. (1967) Spectrophotometric determination of serum antioxidants. Annal Clin. Biochem. London. 9: $42-50$.

13. Quaife M.L., Scrimshaw N.S. and Lowry O.H. (1949) A micromethod for assay of total tocopherols in blood and serum. J. Biol. Chem.180: 1229.

14. Lowry O.H., Quaife M.L. and Scrimshaw N.S. (1949) A micro method for assay of total antioxidants in blood and serum. $J$. Biol. Chem. 180: 1249.

15. WHO/MONICA (1992) The role of antioxidants in Prevention of Diabetes Mellitus.WHO Technical Report Series. Geneva. 727.

16. IVACG. (1996) IVACG Policy Statement on Vitamin A, Diarrhea and
Measles, Washington, USA., 5-28.

17. Sankale N. and Mazer A. (1992) "Guide de Medicine en Afrique et Ocean Indiena Edicef. France. 1000-1003

18. Wongsiriroj N. and Blaner W.S. (2004) Vitamin A Storage and Action in the Liver. Sight and Life Newsletter 2: 4-10

19. Dosso D. K., Rana S.V., Offe-Amoyaw D., Tete D. and Maddy S.Q. (2001) Total Antioxidant Status in non-insulin-dependent diabetes mellitus patients in Ghana. West Afr. J. Med. 20: 148 - 186.

20. Yochum L.A., Folsom A.R. and Kushi L.H. (2000) Intake of Antioxidant vitamins and Risk of Death from Stroke in Postmenopausal Women. Am. J. Clin. Nutr. 72: $476-48$

21. Stahl W. and Sies H.(1997) Antioxidant defense: Vitamin E and C and Carotenoids. Diabetes 6: $\mathrm{S} 14-1$

22. Catherwood M.A., Powell L.A., Anderson P., McMaster D., Sharpe P.C. and Trimble E.R. (2002) Glucose-induced Oxidative Stress in Mesangial Cells. Kidney Int. 6: $599-608$

23. Rasilainens S., Nieminen J.M., Levonen A.L., Otonkoski T. and Lapatto R. (2002) Dose Dependent Cysteine-Mediated Protection of Insulin-Producing Cells Damage by Hydrogen Peroide. Biochem. Pharmacol. 63: 1297-1304.

24. Cariello A., Quatraro A. and Giugliano D. (1992) New Insight on Non-Enzymatic Glycosylation May Lead to Therapeutic Approaches for the Prevention of Diabetic Complications. Diabet Med. 9: 297 -299

25. Baynes J.W. (1991) Role of Oxidative stress in development of complications of diabetes. Diabetes 40: 405 - 412

26. Fuller C.J., Chandalia M. and Garg A. (1996) RRR-Alpha Tocopheryl Acetate Supplementation at Pharmacologic Doses Decreases Low-Density-Lipoprotein Oxidative Susceptibility but not Protein Glycation in Patients with Diabetes Mellitus. Am. J. Clin. Nutr. 63: 753 - 759

27. Schneider R.H., Castillo-Richmond A. and Alexander C.N. (2000) Effects of stress reduction on carotid atherosclerosis in hypertensive African-Americans. Stroke 31: 
568-573.

28. Chung T.W., Yu J.J. and Liu D.Z. (1998);

Alpha tocopherol reduces lipidperoxidation stress of erythrocyte membrane in type 2

diabetes mellitus patients with retinopathy.

Diabetes 15: 380 - 385. 